\title{
High-pressure cryogenic distillation data for improved LNG
}

\section{production}

Valérie Sage ${ }^{a}$, Philip Hazewinkela ${ }^{a}$ Martin Khamphasith ${ }^{b}$, Brent Young ${ }^{c}$, Nick Burke ${ }^{d}$, Eric F. May ${ }^{b}$

${ }^{a}$ CSIRO Energy, 26 Dick Perry Avenue, Kensington, WA 6151, Australia

${ }^{b}$ Australian Centre for LNG Futures, The University of Western Australia, Crawley, WA 6009, Australia

${ }^{c}$ Department of Chemical \& Materials Engineering, The University of Auckland, 1010, New Zealand ${ }^{d}$ CSIRO Energy, Private bag 10, Clayton South, VIC 3169, Australia

\begin{abstract}
Current methods and models to reliably simulate and predict cryogenic column performance, essential for designing and operating commercial Liquefied Natural Gas (LNG) distillation and scrub columns, are currently lacking accurate and reliable empirical data at industrially-relevant conditions (high pressure/low temperature). This leads to conservative design for safety purposes. This paper endeavours to address this gap. Through the use of a unique cryogenic distillation column, critical experimental data at industry-relevant conditions (up to $4 \mathrm{MPa}$ and down to $233 \mathrm{~K}$ ) have been collected. This constitutes an essential step towards future optimization of LNG scrub columns, eliminating the requirement for over-design, thus improving production and reducing costs. The experimental data were compared with the predictions of the steady state model and showed reasonable agreement, although discrepancies were observed, confirming the need to improve models of LNG scrub columns.
\end{abstract}




\section{Keywords}

LNG; cryogenic distillation; scrub column; model; high pressure 


\section{Introduction}

Liquefied Natural Gas (LNG) is playing an increasingly important role in the world energy mix. In a LNG production plant, prior to liquefaction, natural gas produced from geological sites must be processed to filter out impurities like $\mathrm{CO}_{2}$ and $\mathrm{H}_{2} \mathrm{O}$, and recover valuable components such as propane and butane (collectively known as LPGs). The recovery of these LPGs occurs in the LNG scrub column, which is a cryogenic distillation tower designed to separate heavy hydrocarbons from the lighter components in the natural gas and thereby prevent compounds heavier than ethane from entering the main cryogenic heat exchanger (MCHE) where liquefaction occurs. The construction and operation of a liquefaction facility requires a significant expenditure of capital, and small improvements in the design of these facilities has the potential to reduce significantly the total cost of capital investment.

In designing and operating commercial LNG scrub columns, engineers often apply design margins to account for the uncertainties resulting from simulations of the process. A major source of uncertainty in such simulations is the prediction of thermodynamic properties by equations of state (EOS) at the high-pressure, low temperature conditions encountered in the scrub column. The most widely used EOS are the cubic functions of Peng and Robinson (PR) [1] and the Soave, Redlich and Kwong (SRK) equations [2], which are computationally efficient when it comes to the description of multi-component mixtures and have been shown to be as accurate as alternative, more complex EOS in the description of vapour-liquid equilibrium (VLE) in such systems. However, May and coworkers $[3,4]$ have shown that while cubic EOS represent VLE data accurately at low pressure, above $4 \mathrm{MPa}$ their deviations grow systematically with increasing pressure as the mixture critical point is approached. Importantly, predictions for the relatively simple binary mixture (methane $+n$-butane) show a deviation of up to $10 \%$ compared to experimental VLE data [3]. This inability of available EOS in process simulators to reliably predict the VLE within LNG scrub columns is particularly problematic because operation at higher pressure would lead to increased LPG recovery. However it is 
imperative that the pressure does not increase to the point where the fluids in the column become supercritical and the separation process fails. Therefore, being able to estimate more accurately the critical point for such operations is essential for optimised operation.

Another source of uncertainty in the design and operation of the scrub column is the estimation of tray or stage efficiencies, which characterise the fact that the separation within the column is dynamic in nature and potentially varies with flow rate. Design correlations exist to estimate the actual number of stages (or the column height) corresponding to a given number of theoretical or ideal stages, by using the concept of column overall tray efficiency. For many decades, the O'Connell empirical correlation [5] has been one of the industry standards for tray efficiency calculations because of its simplicity compared to more fundamental but also much more complex mass transfer equations [6-8]. Despite its known inaccuracies, this approach has been used successfully for the design of new columns by applying some margin, and to estimate the efficiencies of existing columns [8]. However, these design and operating margins constitute increases to the cost of constructing and operation of LNG scrub columns that potentially could be reduced if a more rigorous method based on fundamental mass-transfer considerations was available for estimating the impact of dynamic effects on LNG scrub columns.

These two aspects, namely the mass transfer effects and the vapour liquid equilibrium, are very closely linked. Kister and co-workers have shown that errors in VLE data can have a major effect on mass transfer rates and tray efficiency calculations $[9,10]$. Improvements in the description of VLE for multi-component hydrocarbon mixtures at high pressures and low temperatures have been made and are the subject of ongoing research $[1,3,4,11-14]$. In this work, we report the utilisation of a new and unique pilot-scale cryogenic scrub column facility for testing high pressure cryogenic distillation in LNG applications and acquiring significant and reliable empirical data. Here we present the first results obtained with this facility, together with the predictions of a simple model, when the column was used to fractionate a natural gas-like mixture at conditions ranging from 233 to $283 \mathrm{~K}$ 
and at pressures up to $4 \mathrm{MPa}$. Randomly packed glass beads were used as the column internals for this preliminary work. The validation by the model of the experimental apparatus and the empirical data collected will validate the approach and its suitability for future model improvements, where Oldershaw trays will also be inserted to facilitate the scale-up of results obtained to industrial applications [15].

\section{Experimental}

\subsection{Pilot-scale cryogenic distillation column}

A unique pilot-scale cryogenic distillation column (CDC) has been developed, operating at cryogenic temperatures and high pressure, which can be used for scrubbing, distillation, or absorption processes. This stainless steel column was $2 \mathrm{~m}$ in length, with an internal diameter of $54.75 \mathrm{~mm}$ and an internal vessel volume of $4.40 \mathrm{~L}$. Glass beads with a density of $c a .0 .58$ were used, giving a column free volume of $c a .1 .1 \mathrm{~L}$. The volume occupied by the temperature transducers penetrating into the bed was negligible and not considered in this column volume calculation. The detailed CDC characteristics and operating parameters are presented in Table 1 and its schematic in Figure 1.

Table 1. CDC characteristics and operating parameters

\begin{tabular}{l|l|l}
\hline Column Characteristics & Length & $2 \mathrm{~m}$ \\
Internal diameter & $54.75 \mathrm{~mm}$ \\
Internals & Randomly packed glass beads \\
Total column volume & $4.4 \mathrm{~L}$
\end{tabular}




\begin{tabular}{|c|c|c|}
\hline & $\begin{array}{l}\text { Packing volume } \\
\text { Void volume }\end{array}$ & $\begin{array}{l}2.55 \mathrm{~L} \text { (0.58 volume fraction } \\
\text { of total volume, [16]) } \\
1.85 \mathrm{~L}\end{array}$ \\
\hline Operating Parameters & $\begin{array}{l}\text { Temperature range } \\
\text { Pressure } \\
\text { Flow rate }\end{array}$ & $\begin{array}{l}203 \mathrm{~K} \text { to ambient+ } \\
\text { Up to } 5 \mathrm{MPa} \\
\text { Up to } 20 \mathrm{SLPM}\end{array}$ \\
\hline
\end{tabular}

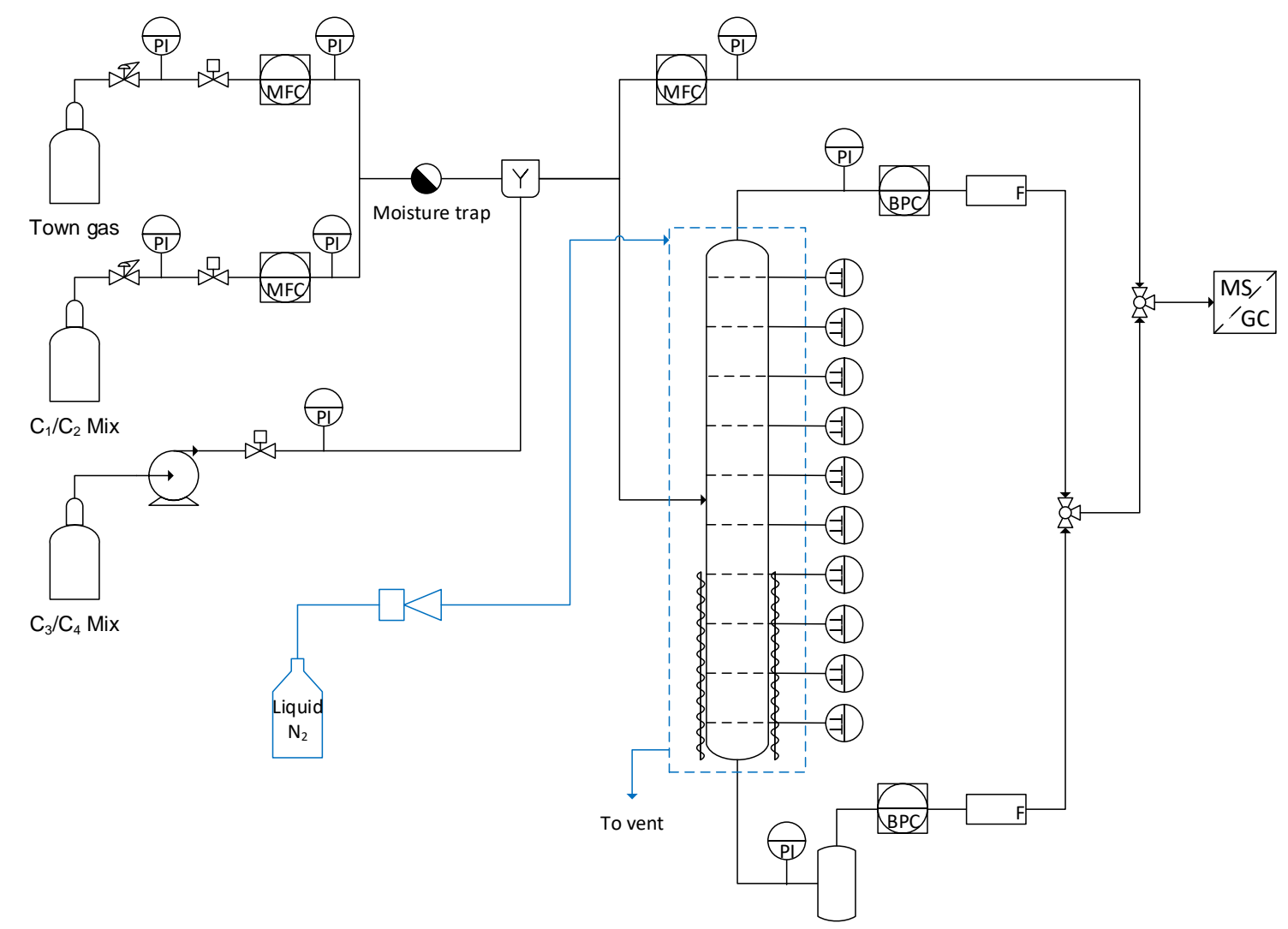

Figure 1. CDC schematic (MFC: mass flow controller; BPC: back pressure controller; F: flow controller; TT:

temperature transducer; MS: mass spectrometer; GC: refinery gas analyser).

The cryogenic distillation column was housed in an insulated cold box, and cooled with a cryogenic vapour jet cooling device, while heating devices were also used to allow full control of the column temperature and temperature gradients along the column, down to $213 \mathrm{~K}$ on the overhead product stream and up to $300 \mathrm{~K}$ on the bottom stream. The column temperature was monitored by 10 
temperature transducers located at regular intervals along the column. The column pressure was controlled with back pressure controllers (BPC) on both overhead and bottom streams, while the outlet flows were controlled from the bottom stream. A flow controller on the bottom stream was used to control the outlet stream flows. A vessel with a volume of $0.15 \mathrm{~L}$ and heated up to $340 \mathrm{~K}$ located at the bottom of the scrub column was used as both a buffer and vaporizer before the bottom product stream was sent for composition analysis.

Desired feed gas composition was achieved by blending multiple gas streams (town gas, enriched with a $C_{1} / C_{2}$ mix). Additional heavy enrichment of the feed stream was achieved by feeding heavier hydrocarbon components $\left(C_{3} / C_{4}\right.$ mix $)$ as liquids at high pressure to the gas phase feed stream. The liquid hydrocarbon stream was vaporised upon entering and mixing with the gas phase stream. Blending of the gas and liquid hydrocarbon streams resulted in a multi component homogenous gas phase feed stream analogous in composition to natural gas (see Table 2). The feed point was located centrally along the column $1000 \mathrm{~mm}$ from the top. The temperature of the feed gas stream as it enters the column was $296 \mathrm{~K}$. Sulphur components and water were removed prior to the analogue natural gas mixture being fed to the column.

Full compositional analyses of both product streams and feed stream were performed on-line either by mass spectroscopy (Pfeiffer Omnistar GSD 320 MS) or gas chromatography (refinery gas analyser, RGA) equipped with a Flame Ionisation Detector (FID) and two Thermal Conductivity Detectors (TCD), using HP-AL/S, Molsieve 5A 60/80 mesh, and HayeSep Q 80/100 mesh columns respectively. $\mathrm{N}_{2}$ was used as internal standard. The calibration of all gas flow rates was conducted with a volumetric flow meter (Bios 220). 


\subsection{Cryogenic distillation of natural gas}

A start-up procedure was followed to bring the column to its steady state operating conditions. Once the desired operating temperature profile along the column was reached, the specified blended feed gas composition (an example of a typical composition is presented in Table 2) was directed to the column and a stabilisation period of several hours was observed. Parameters such as flow rate and product stream ratios were set for each unique experiment. During a single experimental run, consisting of up to 12 hours of run time, a number of parameters could be changed. Data were collected during both steady state and dynamic column operations.

Table 2. Typical feed gas composition

\begin{tabular}{l|c}
\hline Gas & Composition (mol\%) \\
\hline $\mathrm{CH}_{4}$ & 80.9 \\
$\mathrm{C}_{2} \mathrm{H}_{6}$ & 9.0 \\
$\mathrm{C}_{3} \mathrm{H}_{8}$ & 3.9 \\
$\mathrm{C}_{4} \mathrm{H}_{10}$ & 1.6 \\
$\mathrm{CO}_{2}$ & 3.7 \\
$\mathrm{~N}_{2}$ & 0.9 \\
\hline
\end{tabular}

The temperature profile along the column, the column pressure, the volumetric flow rates of the feed, overhead, and bottom streams, as well as their molar compositions were controlled and monitored throughout the experiment. A typical experimental temperature gradient along the column is presented in Figure 2. All experimental runs were reproducible and the experimental uncertainties of mole and mass balances for carbon for each experiment closed to within $5 \%$. The 
volumetric flow rates and molar compositions of the feed, overhead, and bottom streams of the experiments presented here are detailed in the supplementary data (Table S1).

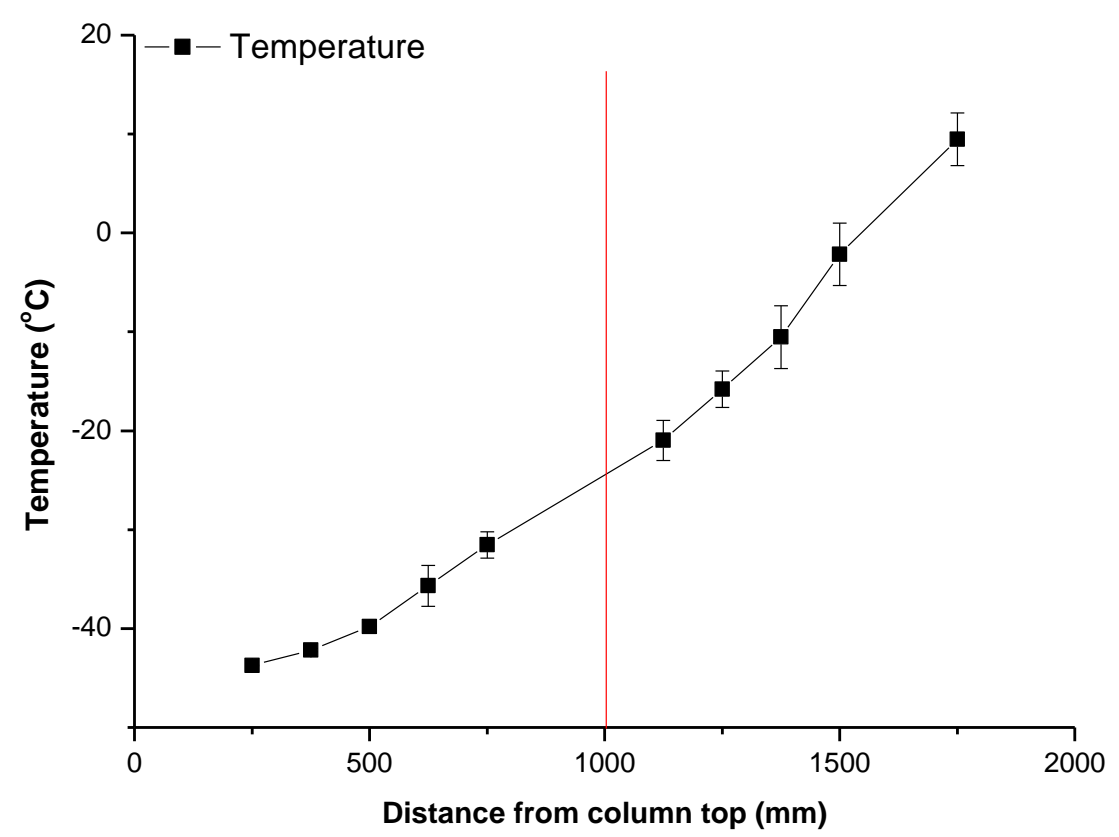

Figure 2. Temperature profile inside the CSC. The red line represent the feed injection point.

\section{Steady-state and dynamic models of CDC column}

\subsection{Model description}

The traditional approach to model a distillation column is to use an integrated column module directly available from the unit operation palette in a simulation software package such as VMGSim [17]. The cryogenic scrub column in this work somewhat differed to a classic column in that there was no condenser or reboiler. The software package also offers the use of a column section, which potentially could be a more suitable model for the description of the physical scrub column.

However, this column section model was not used because the temperature profile within pre-built column section could not be modified easily to match the temperature profiles actually measured in the experiment. 
Accordingly, the modelling approach used here considered the column simply as a series of separators connected together via recycle streams, with each separator temperature set to force agreement with the overall temperature profile measured for the actual column. This model was implemented within the process simulation software package VMGSim, Version 9.5 [17], and the fluid properties package selected was the Advanced Peng Robinson (APR) for Natural Gas ("APR for Natural Gas 2" APRNG2) [18], which has all the characteristics of the Peng Robinson model plus volume translation for accurate liquid phase density estimations using the modified Peneloux idea [19].

To determine the number of stages that should be used in the model to represent the packed column, a 'rule of thumb' for the height equivalent to a theoretical plate (HETP) presented by Kister [7] was used. For columns diameters less than $30.5 \mathrm{~cm}(1 \mathrm{ft}$.), the rule of thumb suggests the HETP should be $30.5 \mathrm{~cm}$ and so the number of theoretical stages required $(\mathrm{N})$ can be derived from the total column height $(\mathrm{H})$ as in Eq. (1).

$N=H / H E T P=2 m / 0.305 m=6.55$

This first approximation indicates that the required minimum number of theoretical stages to represent the experimental scrub column used in this work was seven. However, the temperature profile along the column was measured physically with 10 temperature transducers. Using only seven separators thus required that the experimental temperature profile be fitted to a polynomial function, which was in turn used to interpolate the temperature appropriate to each of the model's seven separators.

To identify the impact of this approximation, the number of separators used in the simulation was adjusted over a 3 to 18 range with the upper and lower temperature limits. This sensitivity study also allowed for the effects of both numerical discretisation and the applicability of the Eq. (1) to the estimation of the HETP to be investigated. The results of the sensitivity study are shown in Figure 3 and reveal that the predicted product compositions become independent of the number of 
separators used above a threshold of 10 . Since this was also consistent with the number of temperature transducers used to measure the column temperature profile in the experimental setup, a model containing 10 separators was selected for all further simulations. The general model, with a variable number of separators, is illustrated schematically in Figure 4.
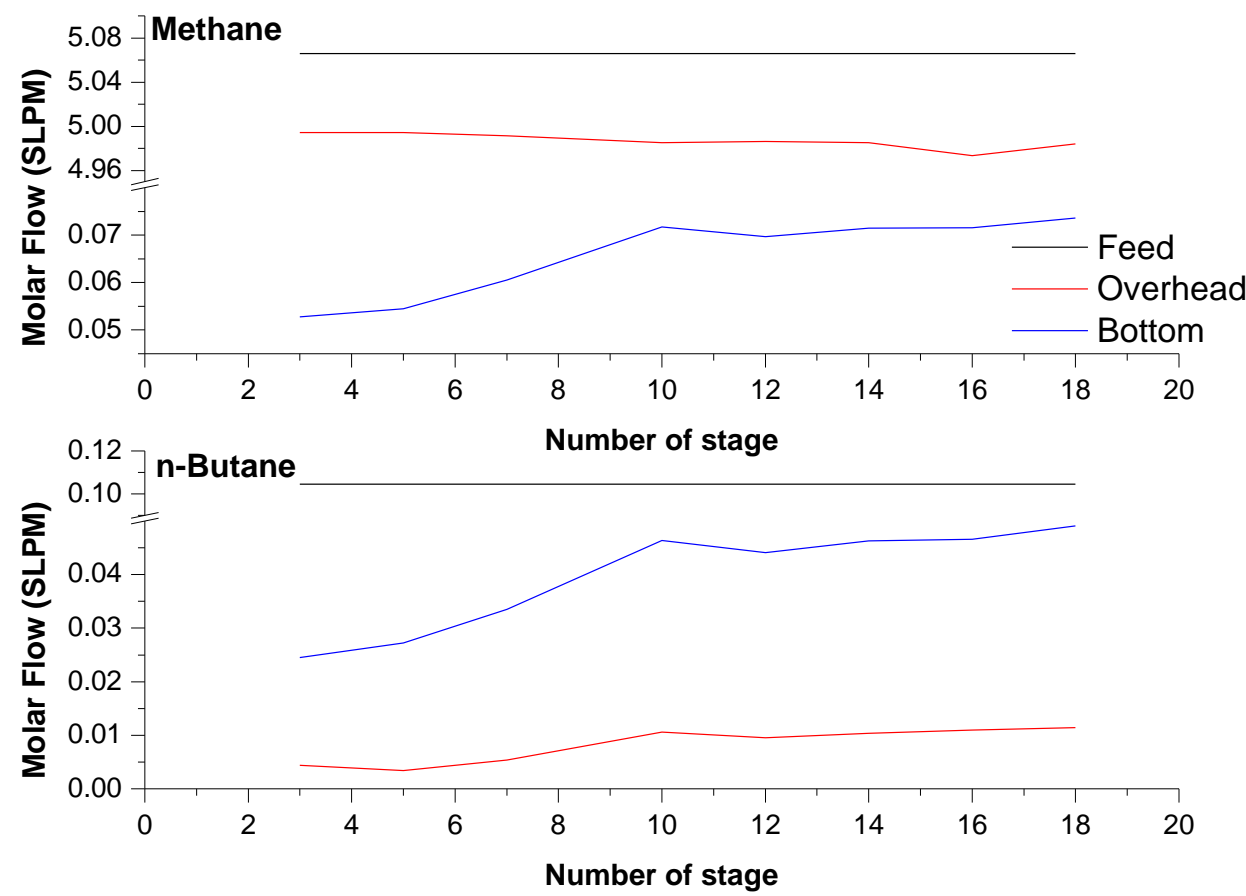

Figure 3. Change in methane (top) and butane (bottom) molar flows with number of stages. 


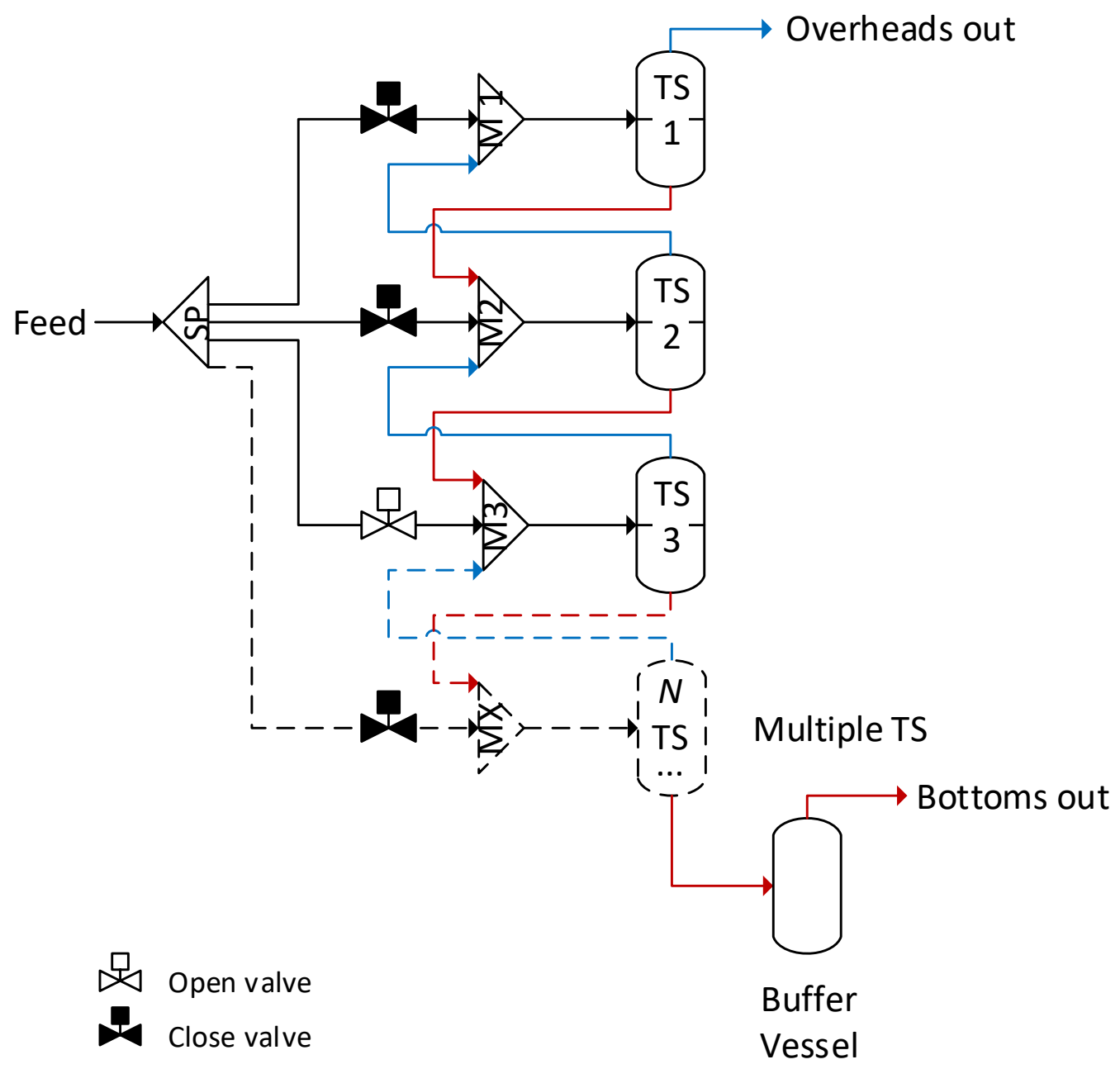

Figure 4. Schematic of the scrub column model with various theoretical stages (TS) (SP: splitter; M: mixer).

In this relatively simple steady state model, the feed conditions were specified, as well as the temperatures of both the bottom and overhead streams, which were respectively $240 \mathrm{~K}$ (temperature of the buffer vessel) and $231 \mathrm{~K}$. The inlet stream to one separator was the combination of the bottom stream from the top separator with the overhead stream from the separator above using a mixer. The compositions and flowrates of the bottom and overhead streams were calculated by the model.

In dynamics mode, some basic design information such as the equipment sizes must be specified. An important assumption made in the dynamic model was the volume occupied by the random packing. Broadly speaking, hard perfect spheres randomly put into a recipient occupies a volume fraction of 
0.58 of the total volume [16]. The experimental column had an internal volume of approximately 4.4 L. Therefore, the volume occupied by the packing $\left(V_{p}\right)$ and the void volume $\left(V_{v}\right)$ were approximately $2.55 \mathrm{~L}$ and $1.85 \mathrm{~L}$ respectively, and the volume occupied by one separator $\left(V_{s}\right)$ can be calculated as in Eq. (2). This volume was approximately $0.18 \mathrm{~L}$ for 10 theoretical stages.

$V_{S}=V_{p} / N$

The inlet and outlet nozzles diameters of the mixers used to mix the various streams were specified at $1 \mathrm{~cm}$. It was experimentally possible to select the feed location on the CDC (see Section 2.1) and this was represented in the model by a splitter (SP) with on-off valves that enabled the feed stream to be sent to the desired plate. The buffer vessel with a volume of $0.15 \mathrm{~L}$ and the back pressure controllers on both outlet streams were also modelled in the simulation.

The fractionation experiments were carried out for various feed flowrates and fixed bottom flowrates. The model was then used to predict the composition and molar flowrates of the overhead stream, knowing the feed and bottom streams composition and flowrate.

\section{Results and Discussion}

\subsection{Steady state}

Parametric studies were performed to test the performance and validity of the model. The experimental data were compared to the predictions of the APRNG2 EOS in the VMGSim software. The simulation followed the same sequential steps as the experiments, and in both cases, steadystate was reached before collecting data and making subsequent changes to some process variables (flow rate and product stream ratios).

Figure 5 compares the results of the steady state composition of the overhead and bottom product streams predicted by the model with the experimental data, for a specific set of experiments ( 6 SLPM feed flow, and a bottom to feed ratio of ca. 0.4) and Figure 6 shows the recovery of each 
compound in the overhead and bottom streams. There was a generally reasonable agreement between the model and the experiments, and most of the LPGs were separated from the natural gas stream and recovered in the bottom products. Figure 7 shows the deviation in composition between the experimental data and the model (as a percent of the mole fraction predicted by the model). For methane and ethane, the deviations were comparable with the uncertainty due just to the material balance error achieved in the experiment. For propane, the deviation were significantly larger than the experimental uncertainty for both the overhead and bottoms streams. The highest deviation was observed for butane in the overhead stream; however, this mostly reflect the large experimental uncertainty with the measurement of trace levels of butane concentration.

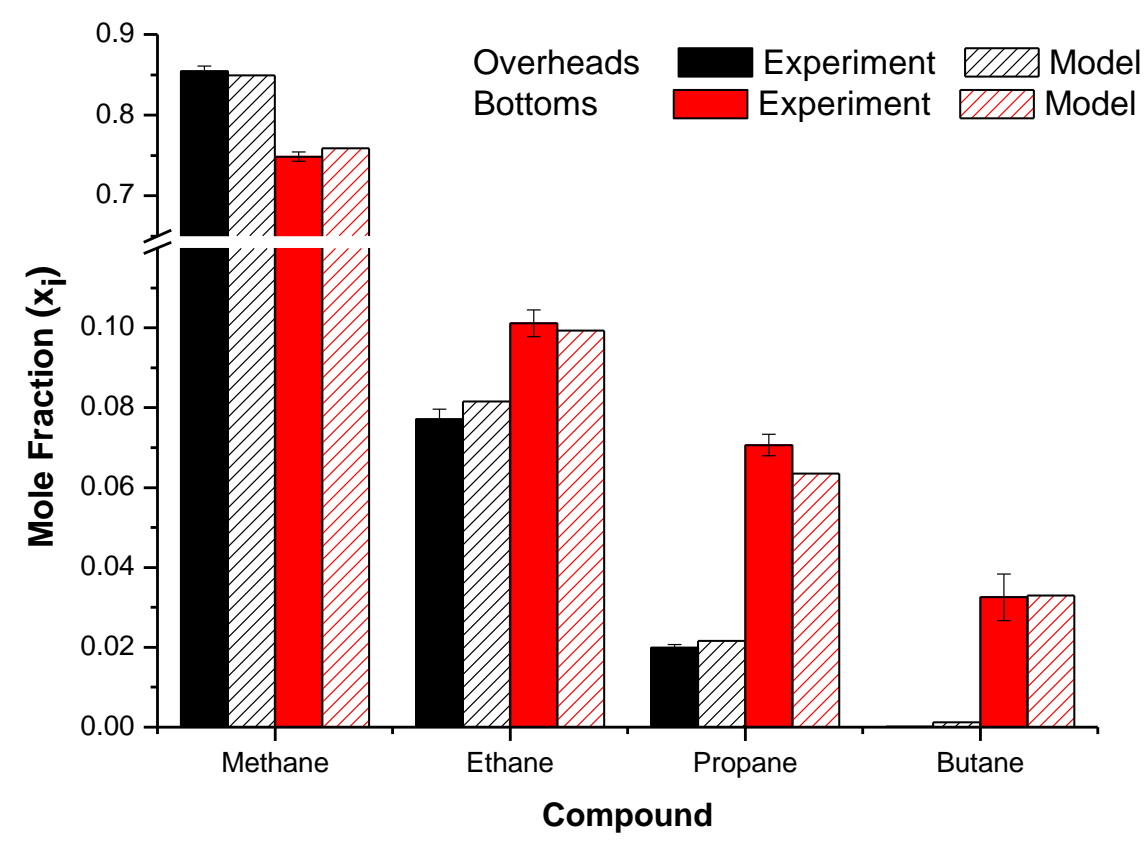

Figure 5. Steady state product streams composition comparison between experiment and model (experimental conditions: 6 SLPM flow, bottom: feed ratio 0.44; experimental error calculated based on individual compound mass balance). $\mathrm{CO}_{2}$ and $\mathrm{N}_{2}$ not shown. 


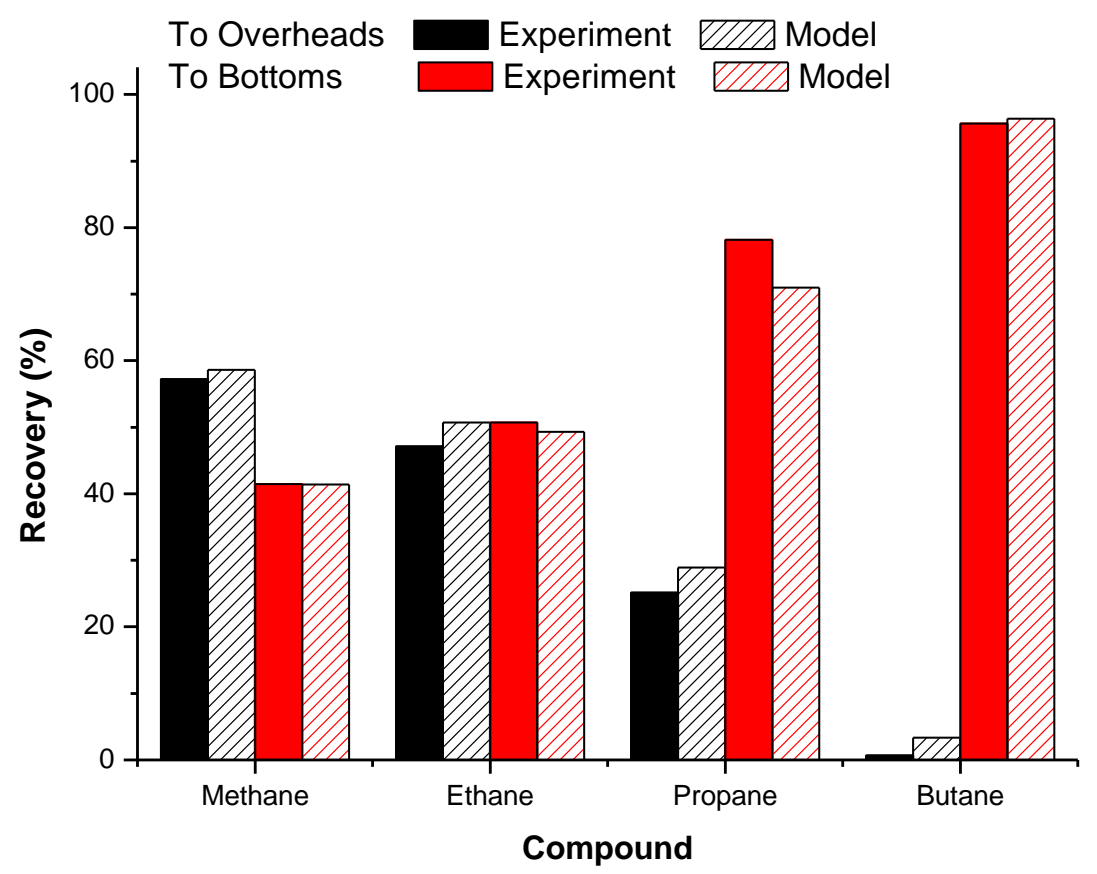

Figure 6. Steady state product streams recovery comparison between experiment and model (experimental conditions: 6 SLPM flow, bottom: feed ratio 0.44$). \mathrm{CO}_{2}$ and $\mathrm{N}_{2}$ not shown.

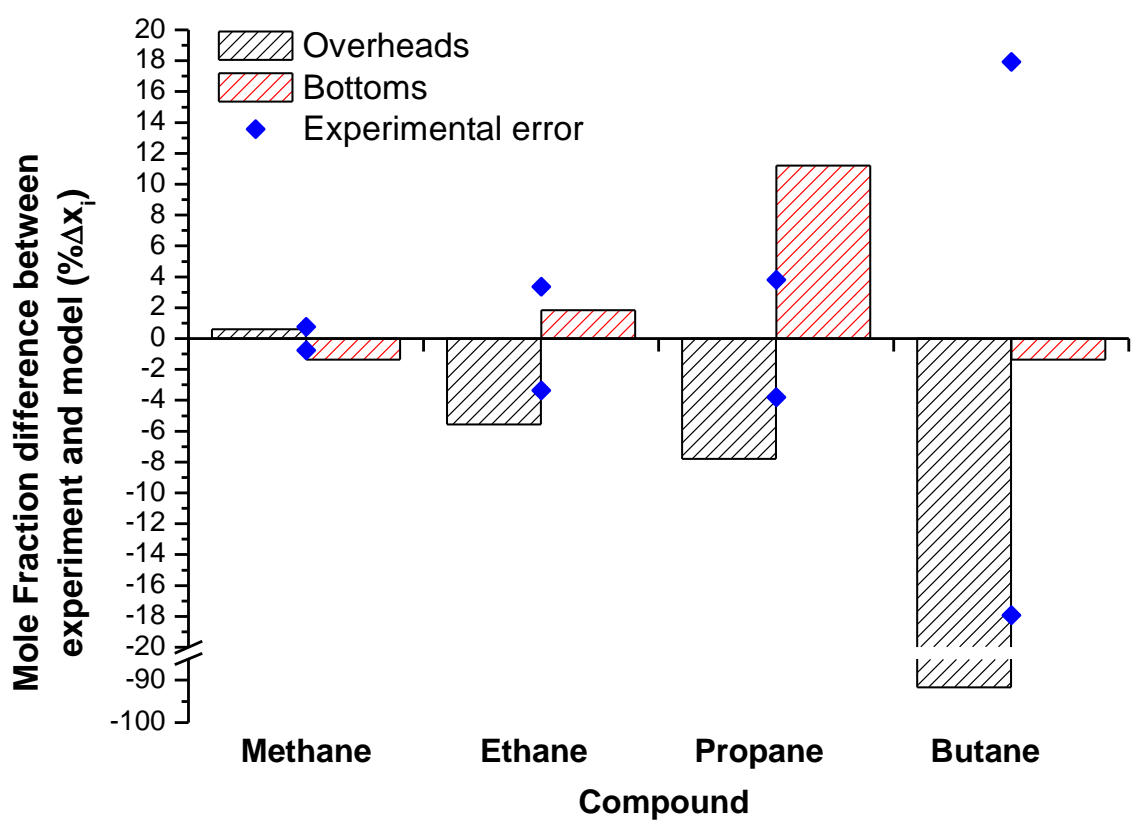


Figure 7. Relative difference in mole fraction between experimental and modelled data $\left(\left(\mathbf{x}_{\text {exp }}-\mathbf{x}_{\text {model }}\right) / \mathbf{x}_{\text {model, }}\right.$ in

\%) for the key components (experimental conditions: 6 SLPM flow, bottom: feed ratio 0.44). $\mathrm{CO}_{2}$ and $\mathrm{N}_{2}$ not shown.

The sensitivity to the HETP value was investigated by changing the number of theoretical stages in the model and considering the resulting deviations between the predicted and measured product mole fraction compositions. The results are shown in Figure 8.

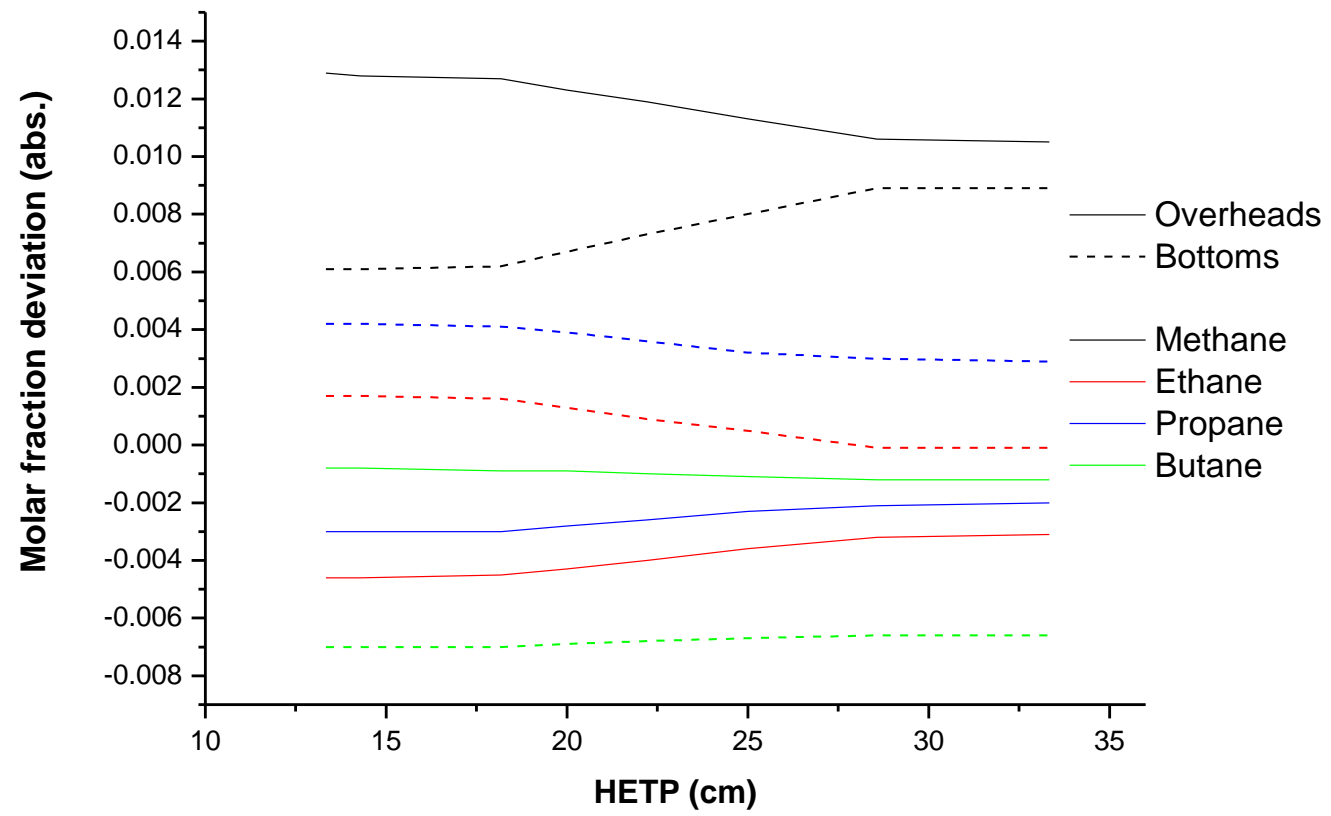

Figure 8. Effect of HETP on molar fraction absolute deviation between the experiments and model predictions.

For all components in both product streams, the absolute deviation in mole fraction decreased with increasing HETP (less theoretical stages), with the exception of methane in the bottom product. The deviations stabilized for a HETP of $28.6 \mathrm{~cm}$, corresponding to seven theoretical stages. This value is very close to the value obtained from the Ludwig rule of thumb as suggested by Kister [7], which predicts a height of packing equivalent to a theoretical stage of $30.5 \mathrm{~cm}$. This result implies this 
relatively simple rule of thumb is adequate for packed columns, at least for the range of residence times considered in these experiments. Future work involving columns with tray internals (Oldershaw trays) will examine the adequacy of equivalent empirical methods to estimate stage efficiencies.

The effect of the flowrates on the HETP required to describe the experimental data was also investigated by increasing the flowrates in the model. The results showed that the product compositions were independent of the flowrates used.

The scrub column product stream flows can be manipulated so as to bias the separation to promote either stripping of the overhead (increasing its methane fraction) or enrichment of the bottoms stream (increasing the LPG content of the bottoms product). This is achieved by varying the heavy product-to-feed ratio (bottom to feed ratio, B:F); a general discussion of using this parameter to manipulate product compositions is given by May et al. [20]. Figure 9 shows a comparison of the measured and predicted compositions as a function of the B:F ratio. The observed results were generally consistent with the trends predicted by the model; small rate-based effects appear to have some impact on the propane recovery achieved. 
Bottom : Feed ratio

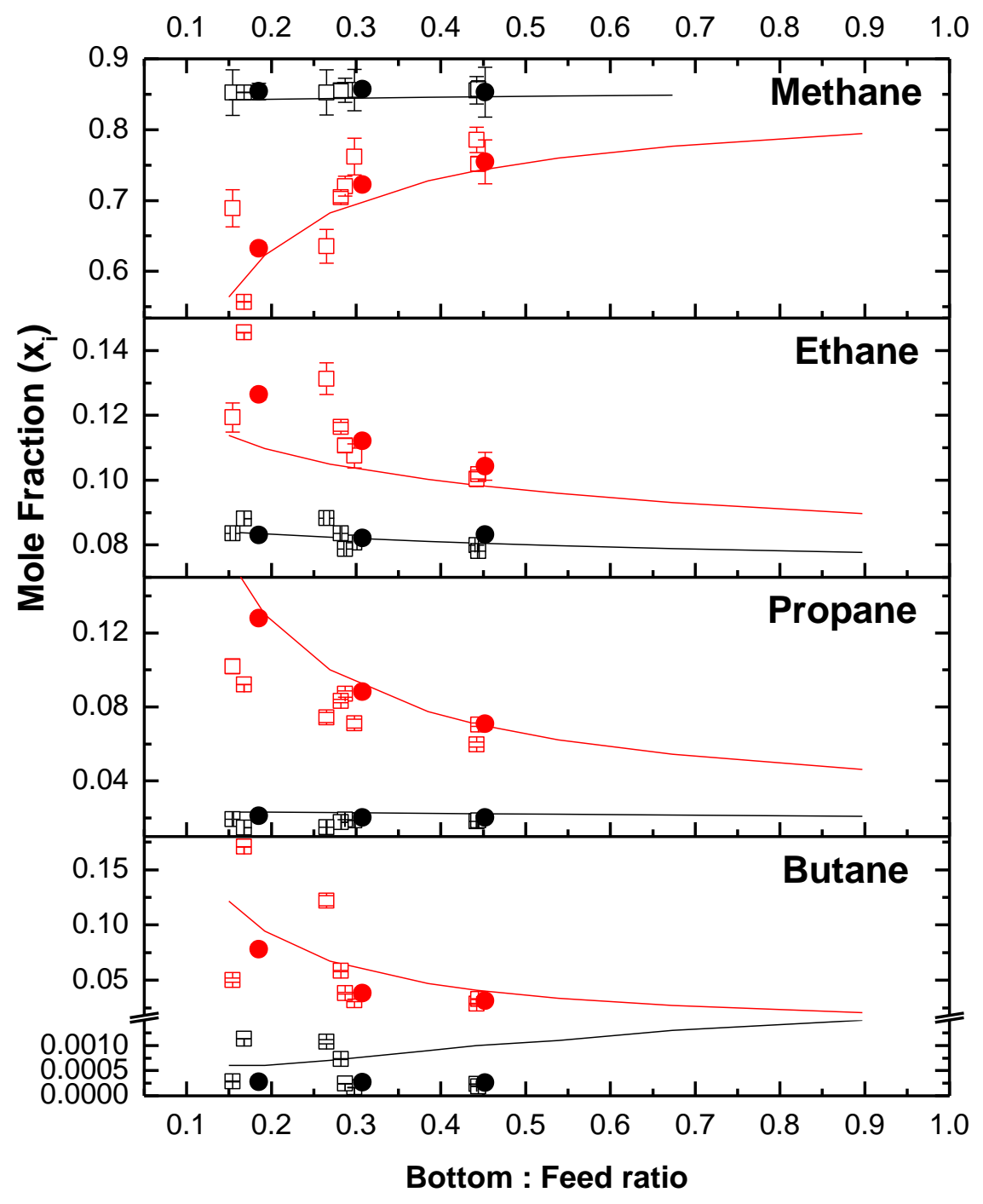

$\square$ Overheads $\square \quad$ Bottoms

Experimental: $\square 6$ SLPM $\bullet 9$ SLPM Model:

Figure 9. Change of stream compositions with bottom to feed ratio (experimental error calculated based on experiment mass balance). The modelled result is independent of flow rate as it is a steady state model.

To investigate rate-based effects on the separation efficiency, a case study was performed. Experiments with similar bottom to feed ratio but different feed, overhead and bottom flows were compared to investigate whether there was a measurable rate-based effect on the overhead composition. Figure 10 shows the overhead composition as a function of feed flow rate for different feed to bottom flowrate ratio. Whether the bottom to feed ratio was maintained constant with 
varying flowrates, or the ratio was modified for the same flowrate, the overhead composition remained mostly similar. Although small, the result obtained for propane indicates that rate-based effects are present.

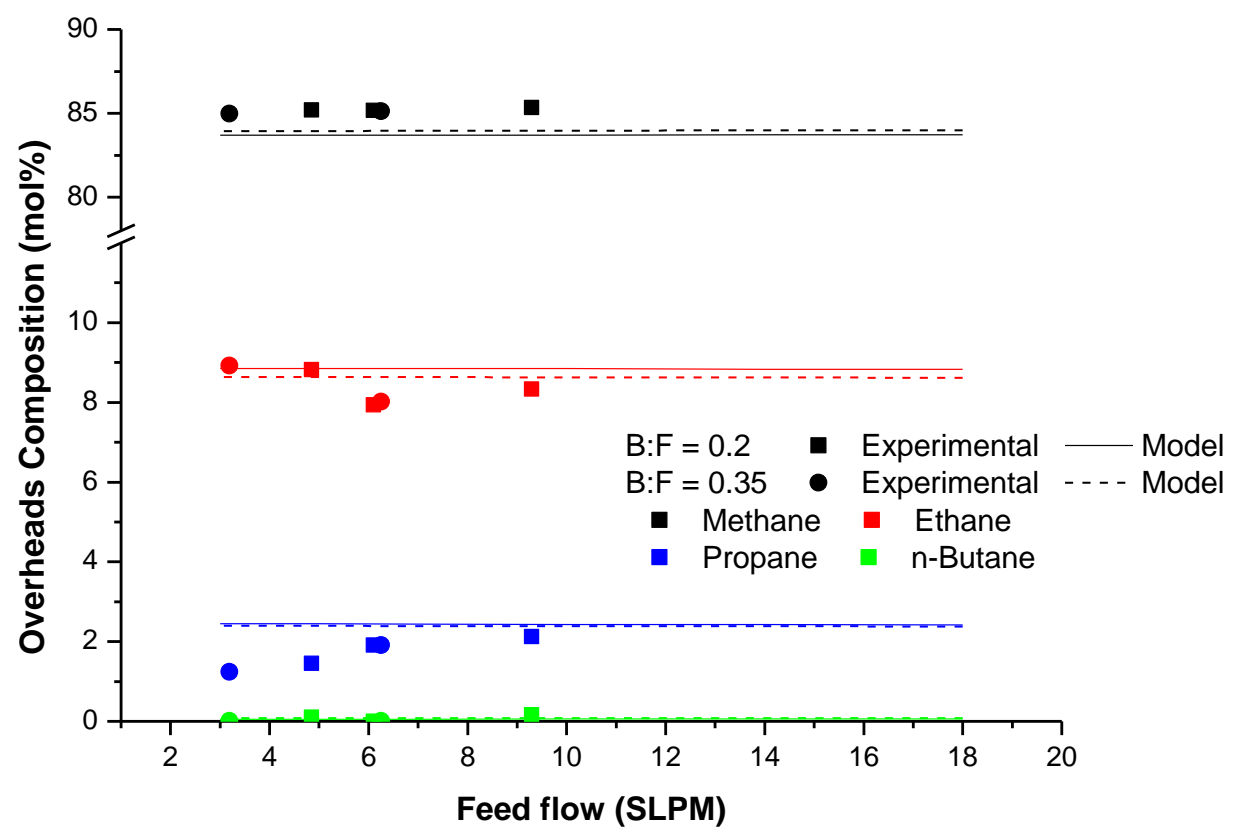

Figure 10. Overheads composition vs feed flow rate for different bottom to feed ratio (dots: experimental data; line: model data). The experimental B:F ratios indicated as 0.2 and 0.35 were in the range $0.18-0.21$ and $0.35-0.37$ respectively.

\subsection{Dynamic transitions}

The flow rates of the product streams, and hence the product streams ratio, were varied during the experiments, introducing periods of transient behaviour. Figure 11 and Figure 12 show the flowrates and composition evolution after changing the bottom flow rate from a high value to a lower value, thus decreasing the bottom to overhead product ratio. The model prediction was in agreement with the experiment data. For the flowrates, the stabilization time between the model and the experiment was comparable, with ca. 30 minutes stabilisation time for the experiment and 15 minutes for the model. Similarly, the bottom stream composition evolution was also comparable, 
but with a longer stabilisation time for the experiment compared to the model (1.5h vs $60 \mathrm{~min}$ respectively). The initial difference in compositions shown in Figure 12 were attributable to the difference between the prediction of the steady-state model and those measured experimentally.

Although the time scales were similar, the dynamics of the response were qualitatively different between model and experiment. The former is a classic response of a stirred tank where compositional equilibrium is instantaneous and the response is determined by the outflow. The data presented here suggest that the experimental dynamic was possibly more complex than the model suggested. For example, the physical distance of the analytical instruments from the column might have also contributed to the difference in stabilisation time between experimental and simulated results, together with hold-up volumes and flow resistances, which were not modelled. Another obvious difference is the controller's response between the experiments and the model, the experimental controller being under-damped compared to the model one.
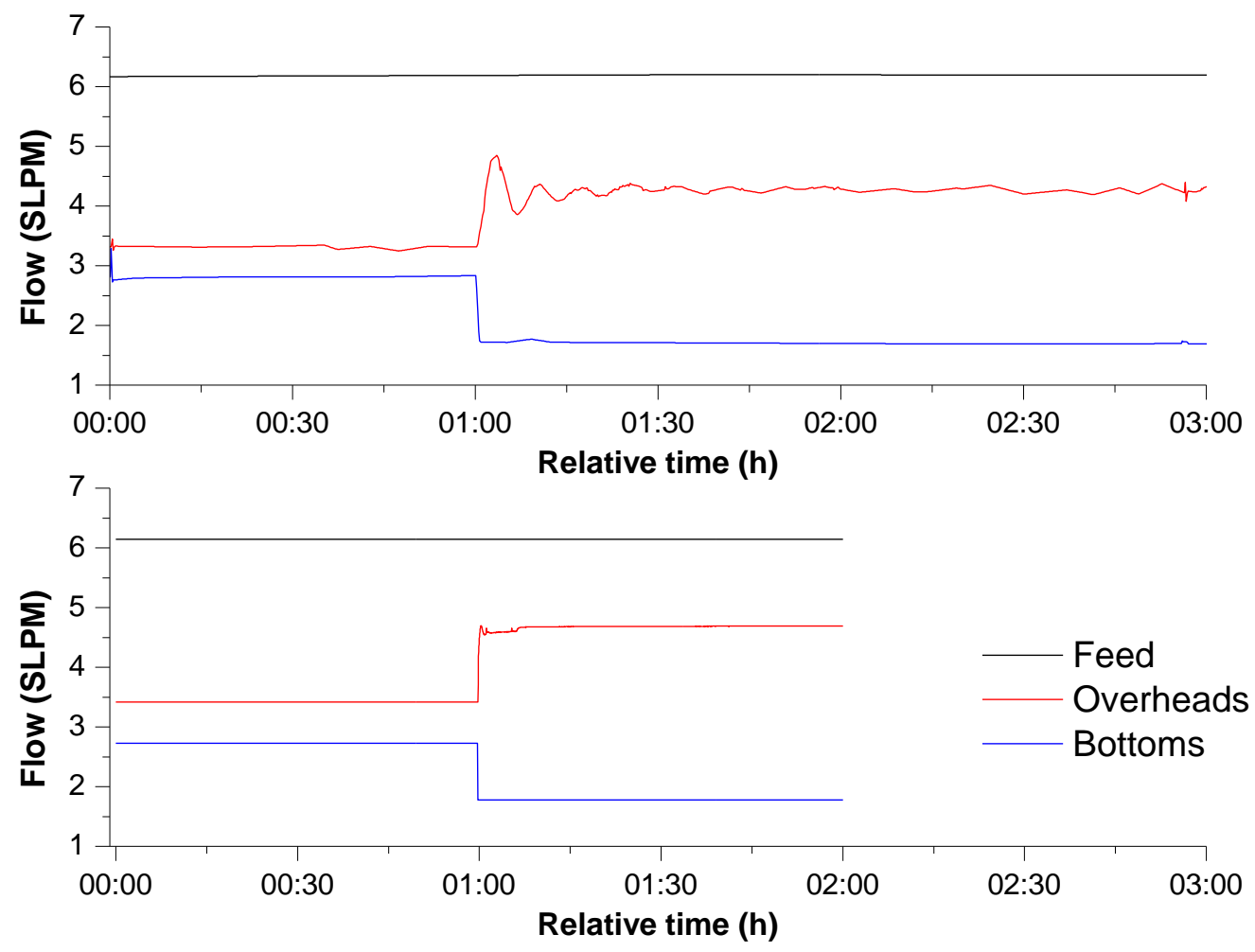
Figure 11. Transient response of total flowrate to change from high to low bottom flow rate. Top:

experimental; bottom: model.
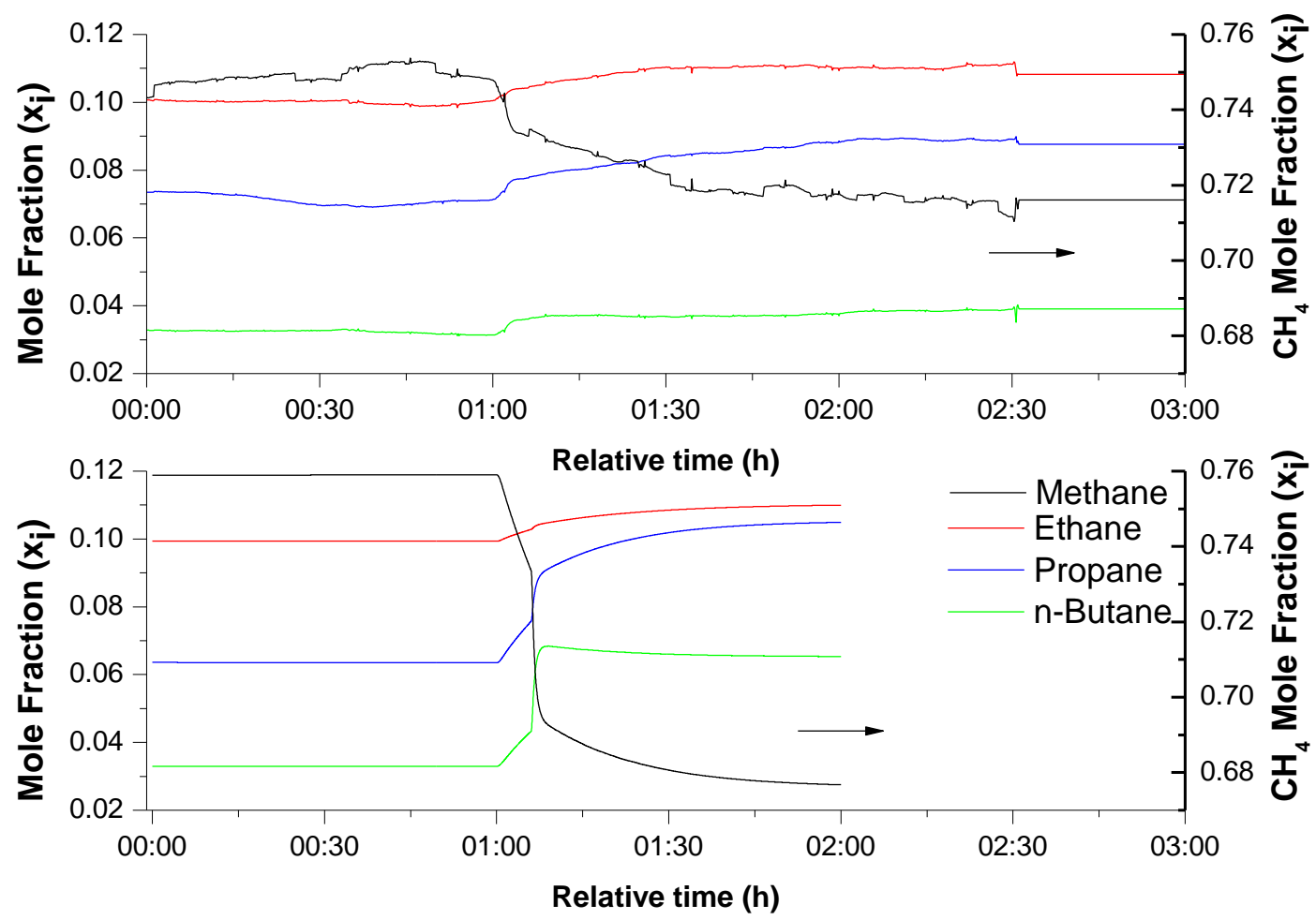

Figure 12. Transient response of bottom stream composition to change from high to low bottom flow rate.

Top: experimental; bottom: model.

\section{Conclusion}

Effective separation of a multi-components natural gas mixture, reflective of LNG feed composition, was achieved experimentally under high pressure cryogenic conditions. Steady state and dynamic process simulations of the column have been constructed to allow comparison of rate-based and equilibrium models with the measured data, and a reasonable correlation was demonstrated between empirical data and model data, demonstrating the suitability of our experimental set-up and data collection approach.

The unique pilot-scale cryogenic distillation column used in this work has demonstrated its effectiveness for the acquisition of critical and reliable empirical data at high pressure, under varying 
conditions. Such data are the cornerstone for the development or more accurate and reliable cryogenic distillation models, which reflect more accurately the operating conditions of scrub columns in LNG industry. They can be used to test process simulations and investigate the effect of various thermodynamic models and generate point efficiency data that can be compared to the O'Connell correlation.

Future improvement in the development of the experimental setup will involve the use of Oldershaw trays as well as the installation of a condenser. This will facilitate the up-scaling of the data obtained and better reflect industrial scrub column applications. Instrumentation of individual part of the column, to measure fluid flows and composition in different section, will also be considered to improve model accuracy and tray efficiency evaluation. The development of an improved correlation for tray efficiencies as a function of fluid properties at high pressure and low temperatures will also be investigated.

This will result in improved efficiency in column design and operation, reduced capital and operating costs, and mitigate unpredictable down-time or lost production in LNG plant due to potential freeze out of the column or MCHE.

\section{Acknowledgement}

This work was supported in part by the ARC Training Centre for LNG Futures (IC150100019).

\section{References}

[1] D.Y. Peng, D.B. Robinson, A New Two-Constant Equation of State, Ind. Eng. Chem. Fundam. 15 (1976) 59-64. https://doi.org/10.1021/i160057a011 
[2] G. Soave, Equilibrium constants from a modified Redkh-Kwong equation of state Chem. Eng. Sci. 27 (1972) 1197-1203. https://doi.org/10.1016/0009-2509(72)80096-4

[3] E.F. May, J.Y. Guo, J.H. Oakley, T.J. Hughes, B.F. Graham, K.N. Marsh, S.H. Huang, Reference Quality Vapor-Liquid Equilibrium Data for the Binary Systems Methane + Ethane, + Propane, + Butane, and + 2-Methylpropane, at Temperatures from (203 to 273) K and Pressures to $9 \mathrm{MPa}$, J. Chem. Eng. Data 60 (2015) 3606-3620. https://doi.org/10.1021/acs.jced.5b00610

[4] T.J. Hughes, J.Y. Guo, C.J. Baker, D. Rowland, B.F. Graham, K.N. Marsh, S.H. Huang, E.F. May, High pressure multi-component vapor-liquid equilibrium data and model predictions for the LNG industry, J. Chem. Thermodyn. 113 (2017) 81-90. https://doi.org/10.1016/j.jct.2017.05.023

[5] H.E. O'Connell, Plate efficiency of fractionating columns and absorbers, Trans. Am. Inst. Chem. Eng. 42 (1946) 741-755.

[6] P.L. Invernici, A.R. Secchi, T.F. Mendes, Overall Efficiency Evaluation of commercial distillation column with two-pass valve trays, in: 2011 AIChE Spring Meeting and Global Congress on Process Safety - The Dr. James Fair Heritage Distillation Symposium conference proceedings, Chicago, IL, March 2011.

[7] H.Z. Kister, Tray Efficiency, in: Distillation Design, McGraw-Hill, New-York, 1992, pp. 365-420 (376).

[8] S.G. Schon, Predicting Distillation Tray Efficiencies Based on Modified O'Connell Correlation Analysis (MOCA) Technique in: 2011 AIChE Spring Meeting and Global Congress on Process Safety The Dr. James Fair Heritage Distillation Symposium conference proceedings, Chicago, IL, March 2011.

[9] H.Z. Kister, Effects of design on tray efficiency in commercial towers, Chem. Eng. Prog. 104 (2008) $39-47$. 
[10] H.Z. Kister, P.M. Mathias, D.E. Steinmeyer, W.R. Penney, B.B. Crocker, J.R. Fair, Equipment for Distillation, Gas Absorption, Phase Dispersion, and Phase Separation, in: D.W. Green, R.H. Perry (Eds.), Perry's Chemical Engineers' Handbook, McGraw-Hill New-York, 2008.

[11] C.J. Baker, T.J. Hughes, B.F. Graham, K.N. Marsh, E.F. May, Rapid hydrocarbon dew points by infrared spectroscopy: Results and validation for binary mixtures of methane + \{propane, isobutane and butane\}, J. Ind. Eng. Chem. 58 (2018) 304-310. https://doi.org/10.1016/i.jiec.2017.09.041

[12] T.J. Hughes, M.E. Kandil, B.F. Graham, K.N. Marsh, S.H. Huang, E.F. May, Phase equilibrium measurements of (methane + benzene) and (methane + methylbenzene) at temperatures from (188 to 348) K and pressures to $13 \mathrm{MPa}$, J. Chem. Thermodyn. 85 (2015) 141-147.

\section{https://doi.org/10.1016/j.jct.2014.12.031}

[13] O. Kunz, W. Wagner, The GERG-2008 Wide-Range Equation of State for Natural Gases and Other Mixtures: An Expansion of GERG-2004, J. Chem. Eng. Data 57 (2012) 3032-3091.

\section{https://doi.org/10.1021/je300655b}

[14] D. Rowland, T.J. Hughes, E.F. May, Extending the GERG-2008 Equation of State: Improved departure function and interaction parameters for (methane + butane), J. Chem. Thermodyn. 97 (2016) 206-213. https://doi.org/10.1016/i.jct.2016.01.005

[15] J.R. Fair, H.R. Null, W.L. Bolles, Scale-up of plate efficiency from laboratory Oldershaw data, Ind. Eng. Chem. Proc. Des. Dev. 22 (1983) 53-58. https://doi.org/10.1021/i200020a010

[16] F.A.L. Dullien, Porous Media: Fluid Transport and Pore Structure, 2nd ed., Academic Press San Diego, California, 1992.

[17] V.M. Group, VMGSim Process Simulator, in, Virtual Materials Group, Inc, Calgary, Alberta, Canada, 2016.

[18] V.M. Group, VMGSim User's Manual, in: V.M. Group (Ed.), Virtual Materials Group, Inc, Calgary, Alberta, Canada, 2016. 
[19] A. Péneloux, E. Rauzy, R. Fréze, A consistent correction for Redlich-Kwong-Soave volumes, Fluid Phase Equilib. 8 (1982) 7-23. https://doi.org/10.1016/0378-3812(82)80002-2

[20] E.F. May, Y. Zhang, T.L.H. Saleman, G. Xiao, G. Li, B.R. Young, Demonstration and optimisation of the four Dual-Reflux Pressure Swing Adsorption configurations, Sep. Purif. Technol. 177 (2017) 161175. https://doi.org/10.1016/j.seppur.2016.12.007 